Short Communication

\title{
AWARENESS OF RISK FACTORS OF DIABETES AND PRACTICES REGARDING ITS PREVENTION AMONG THE ADOLESCENTS
}

\author{
Salman Ansari ${ }^{1}$, Shreyas Samaga ${ }^{1}$, Shrihari Rao ${ }^{1}$, Suraj Gowda ${ }^{1}$, \\ Tariq Mohammed ${ }^{1}$, Swathi Atrolia', Ravi ${ }^{2}$, Rashmi Kundapur ${ }^{3}$ \\ ${ }^{1}$ M BBS Students (III Year), ${ }^{2}$ M edico Social Worker, ${ }^{3}$ Associate Professor, Department of Community M edicine, \\ K.S. Hegde M edical Academy, Nitte University, M angalore, INDIA \\ Correspondence: \\ Rashmi \\ Associate professor, Department of Community M edicine, K. S. Hegde M edical Academy, \\ Nitte University, Deralakatte, Mangalore, Karnataka, India \\ Mobile : +919880496567 E-mail : dr.rashmi.kundapur@gmail.com
}

\begin{abstract}
Introduction : India leads the world with largest number of diabetic subjects, and hence also termed as the Diabetic Capital of the world. Education is the cornerstone of diabetes prevention. Because of lack of awareness, most people suffer from diabetes at an early age. Before population-based interventions can be implemented, an assessment of knowledge and awareness of risk factors for Diabetes and practices to prevent it among adolescents is needed.
\end{abstract}

Aims \& Objectives : To estimate the prevalence of risk factors of diabetes and the practices regarding its prevention among the adolescents

Materials and M ethod : The study was community based cross sectional type. A reviewed, self-prepared questionnaire consisting of questions based on the awareness of the risk factors and the practices regarding its prevention was prepared. Data was collected from 600 adolescents of age group 16-18years. Students from 4 pre-university colleges in Mangalore, Dakshina Kannada district, were selected as the study group.

Results : $4.33 \%$ were aware that smoking was a risk factor for diabetes. $48.33 \%$ of students said that consumption of sweets can lead to diabetes. $8.66 \%$ of students agreed that mental stress can lead to diabetes. Physical inactivity, as a risk factor for diabetes was known by $7.33 \%$ of them. Only $5.5 \%$ and $5.33 \%$ of students were aware that family history and obesity respectively, can lead to diabetes.93.67\% of the students have not had themselves tested for diabetes. $99.16 \%$ of subjects are non-smokers. $98.16 \%$ do not consume alcohol. $53.67 \%$ do not exercise regularly.

Keywords: Diabetes, Adolescents, Risk factors, Exercise

\section{Introduction:}

India leads the world with largest number of diabetic subjects earning the dubious distinction of being termed the "diabetes capital of the world". According to International Diabetes Federation, 1 in 5 of all undiagnosed cases of diabetes and 1 in 4 of all deaths in the world due to diabetes belong to South-East Asian Region (SEAR). It has been ascertained that Access this article online Quick Response Code

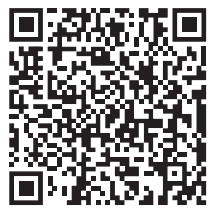

51.1\%of undiagnosed cases in the world belong to the SEAR region.According to the Diabetes Atlas 2012 (5th edition) published by the International Diabetes Federation, the number of people with diabetes in India is expected to rise to around 87.0 million by 2030 unless urgent preventive steps are taken. The prevalence of diabetes is rising all over the world due to population growth, aging, urbanization and an increase in obesity and physical inactivity, especially among the adolescents. Education is the cornerstone of diabetes prevention. Because of lack of awareness, most people suffer from diabetes at an early age. Several risk factors have been identified as contributors to the development of diabetes in youth. These factors include increased body fat and abdominal fat, family history of diabetes, smoking and alcohol ${ }^{[1],[2]}$

Hence, targeting adolescents for prevention is a logical and vital strategy for improving future health worldwide. Before population-based interventions can be 
implemented, an assessment of knowledge and awareness of risk factors for Diabetes and practices to prevent it among adolescents is needed ${ }^{[3]}$. So, our study aims at this assessment.

\section{Aims \& Objectives:}

To estimate the prevalence of risk factors of diabetes and the practices regarding its prevention among the adolescents

\section{Materials and Methods :}

Study technique: Community based cross-sectional study.

Study Sample: Taking into consideration $10 \%$ of the adolescents having knowledge about diabetes using formula, $n=4 p q / L^{2}$, where, $p=10 \%, q=1-p, L=3 \%, n=$ sample size. With a confidence interval of $97 \%$ and power of the study being $80 \%$, we get a sample of 400 . Considering few unfilled questionnaire, an excess of $20 \%$ of the calculated sample was decided i.e. 480 adolescents. A questionnaire consisting of questions that were based on the knowledge, awareness and practices regarding the risk factors of Diabetes was prepared. Students from 4 pre-university colleges in Mangalore, Dakshina Kannada district, were selected as the study group. Data from 600 adolescents of age group 16-18years was collected. Only students willing to participate in the study were included. The questionnaire given was to be filled anonymously. The questions being in English, an oral translation in the local language was given. Sufficient time was given to the students to complete the questionnaire. The data obtained were compiled manually and the results were tabulated.

\section{Results:}

$4.33 \%$ of the students in our study were aware that smoking was a risk factor for diabetes, while $95.67 \%$ were not aware of it. $48.33 \%$ of students said that consumption of sweets can lead to diabetes while $51.67 \%$ of them denied it. $8.66 \%$ of students agreed that mental stress can lead to diabetes. Physical inactivity, as a risk factor for diabetes was known by $7.33 \%$ of them. Only $5.5 \%$ and $5.33 \%$ of students were aware that family history and obesity respectively, can lead to diabetes $.93 .67 \%$ of the students have not had themselves tested for diabetes. $99.16 \%$ of subjects are non-smokers. $98.16 \%$ do not consume alcohol. $53.67 \%$ do not exercise regularly.

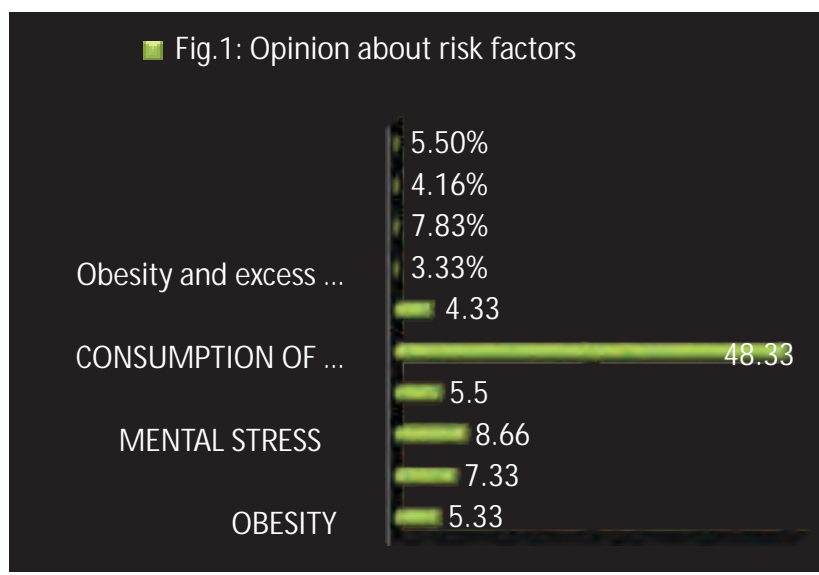

Fig.2: Number Of people tested for diabetes

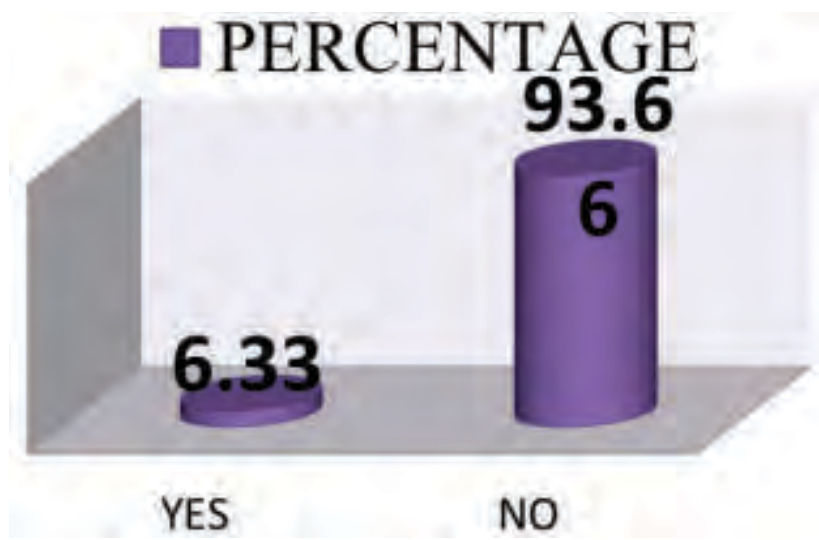

Fig.3: Number of people who exercise

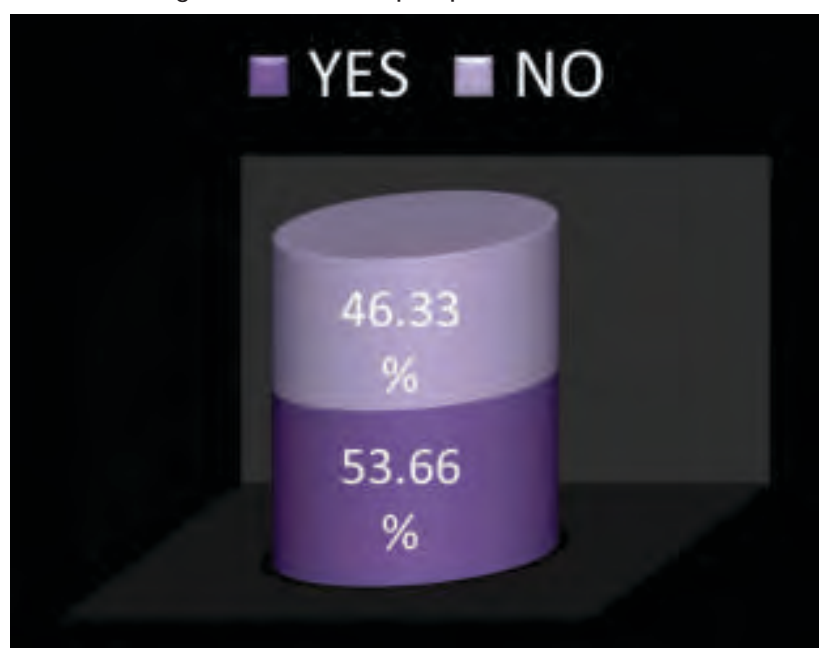


Table.1: Awareness Table

\begin{tabular}{|l|c|c|}
\hline & Yes & No \\
\hline Smoking & $4.33 \%$ & $95.67 \%$ \\
\hline Decreased physical activity & $7.33 \%$ & $92.67 \%$ \\
\hline Family history & $5.5 \%$ & $94.5 \%$ \\
\hline Obesity & $5.33 \%$ & $94.67 \%$ \\
\hline Excess consumption of sweets & $48.33 \%$ & $51.67 \%$ \\
\hline M ental stress & $8.66 \%$ & $91.37 \%$ \\
\hline $\begin{array}{l}\text { Obesity and excess } \\
\text { consumption of sweets }\end{array}$ & $3.33 \%$ & \\
\hline $\begin{array}{l}\text { Decreased physical activity and excess } \\
\text { consumption of sweets }\end{array}$ & $7.83 \%$ & \\
\hline $\begin{array}{l}\text { M ental stress and excess consumption } \\
\text { of sweets }\end{array}$ & $4.16 \%$ & \\
\hline $\begin{array}{l}\text { Family history and excess consumption } \\
\text { of sweets }\end{array}$ & $5.5 \%$ & \\
\hline
\end{tabular}

Table 2 : Practice Table

\begin{tabular}{|l|c|c|}
\hline & Yes & No \\
\hline Tested for diabetes & $6.33 \%$ & $93.67 \%$ \\
\hline Smoking & $0.83 \%$ & $99.16 \%$ \\
\hline Alcohol & $1.83 \%$ & $98.16 \%$ \\
\hline Exercise & $53.67 \%$ & $46.33 \%$ \\
\hline
\end{tabular}

\section{Discussion :}

According to a study in Chennai ${ }^{[4]}, 2.7 \%$ of the subjects knew that obesity was a risk factor for diabetes, while in our study $5.33 \%$ of students knew it.In the study done in Chennai ${ }^{[4]}, 4.7 \%$ of the subjects agreed that decreased physical activity was a risk factor for diabetes, while it was agreed by $7.33 \%$ of adolescents in our study. $4.33 \%$ of the subjects in our study agreed that smoking was a risk factor while only $0.01 \%$ of the subjects in the study done in Chennai agreed to this as a risk factor ${ }^{[4]}$. The study in Chennai was done among a general population while our study dealt with educated adolescents. Hence there is a higher percentage of knowledge in our study. $8.66 \%$ of the subjects in our study agreed that mental stress was a risk factor while it was just $3 \%$ in an African study. Again, this could probably because of a higher level of awareness among the Indian population when compared to that of Africa. 5.5\% of the subjects in our study knew that family history of diabetes is a risk factor while $31.2 \%$ people knew about family history as risk factor in a study done in Chennai. About $48.33 \%$ of subjects in our study agreed that excess consumption of sweets was a risk factor. A similar study in Chennai showed a positive response of $22.2 \%$. This represents the lack of complete knowledge about diabetes. This calls for implementation of better practice methods to popularize the risk factors of the disease.Only the single risk factors were considered as the cause of diabetes by $80.33 \%$ of adolescents, remaining $19.67 \%$ were of the opinion that multiple risk factors caused diabetes. 3.33\% of students agreed that obesity and excess consumption of sweets would lead to diabetes. Decreased physical activity and excess consumption of sweets as a risk factor for diabetes was known by $7.83 \%$ of students. $4.16 \%$ of students knew that mental stress and excess consumption of sweets can be a risk factor for diabetes. Only $5.5 \%$ of students agreed to the increased risk of diabetes with a family history along with excess consumption of sweets. A very high percentage of the students consider diabetes to be caused by a single risk factor. This could probably be because of the various myths that are associated with the disease.

Only $6.3 \%$ of subjects in our study were tested for diabetes, while $93.6 \%$ were not tested for diabetes. InAmerica ${ }^{[5]}$ the number of teenagers who underwent a test for diabetes went from $9 \%$ to $23 \%$ in the last decade.This is because of increased awareness that it can occur at any age and also increased incidence of diabetes in adolescents in the developed countries. Only $0.83 \%$ of the subjects of our study smoke. In a study done in Iran, it was seen that 13.9\% of adolescents smoke regularly ${ }^{[6]}$. Our study shows very low percentage of smokers probably because it is considered a taboo and hence they would not have revealed it to us.1.83\% of subjects agreed that they consume alcohol and $98.16 \%$ say that they do not consume alcohol.In a study conducted in Iceland, it was seen that $28 \%$ of study participants had become drunk once or more often in their lifetime ${ }^{[7]}$.Our study showed that $53.66 \%$ of the subjects exercise regularly while $46.33 \%$ do not.Studies done in Taiwan ${ }^{[8]}$ showed that $80 \%$ of adolescents were engaged in some form of physical activity.Percentage of students engaging in exercise is more in other such countries because they give importance to physical fitness and health and it is an important part of their curriculum. 


\section{Acknowledgement:}

We thank the Head of the department, Dr.Uday Kiran Nalam and all the staff of Community medicine for their immense support during the study

\section{Conclusion :}

A high majority of adolescents are unaware of the risk

\section{References}

1. Arslanian S. Type 2 Diabetes in Children: Clinical Aspects and Risk Factors; Horm Res 2002;57(suppl1):19-28

2. Michael I. Goran, Geoff D. C. Ball, And Martha L. Cruz;Obesity and Risk of Type 2 Diabetes and Cardiovascular Disease in Children and Adolescents,Departments of Preventive Medicine and Physiology \& Biophysics, Keck School of Medicine, University of Southern California, Los Angeles, California 90033;The Journal of Clinical Endocrinology \& Metabolism 88(4):1417-1427

3. ArashMahajerin, Andrew Fras,Thomas E. Vanhecke, Jeremiah Ledesma, Assessment of Knowledge, Awareness and Self-Reported Risk Factors for Type II Diabetes among adolescents; Journal of Adolescent Health; Volume 43, Issue 2, August 2008, Pages 188-190

4. Deepa Mohan, DeepaRaj, CS Shanthirani, Manila Dutta, NC Unwin, A Kapor, V.Mohan; Awareness and Knowledge of Diabetes Mellitus in Chennai-The Chennai urban epidemiology study; JAPI, Volume 53, April 2005

5. Teenage Diabetes Rates Boarlon point with Toom Ash Ashbrook;www.onpoint.wbur.org/2012/05/24/teenage diabetes

6. Hussain HY, Abdulsatar BA.; Prevalence and determinants of tobacco use among Iraqi adolescents: Iraq GYTS 2012;TobInduc Dis. 2013 Jun 28;11(1):14

7. Alfgeir Logi Kristjansson, Inga Dora Sigfusdottir, and John $P$ Allegrante, Adolescent substance use and peer use: a multilevel analysis of cross-sectional population data; Subst Abuse Treat Prev Policy. 2013; 8: 27.

8. Chen LJ, Hassee, FoxKR, University of Bristol, Department of exercise, nutrition and health science, centre for sport, exercise and health, TyndallAvenue,Bristol; Physical activity among Adolescents in Taiwan;Asia Pacific Journal of clinical nutrition 2007 16(2)354-36 factors of diabetes and an even higher group of students believe that diabetes is caused by a single risk factor. The prevalence of smoking and alcohol consumption among the students is very less and a vast majority of them do not exercise regularly. 